\title{
DISCURSO DE PARANINFA, TURMA 2020.1 DO CURSO DE BIBLIOTECONOMIA DA UNIVERSIDADE FEDERAL DO MARANHÃO (UFMA)
}

\author{
Maria da Glória Serra Pinto de Alencar ${ }^{1}$
}

Excelentíssima Senhora Professora Doutora Aldinar Martins Bottentuit, Coordenadora do nosso Curso de Biblioteconomia, na pessoa de quem cumprimento os demais componentes desta sessão solene virtual.

Senhores pais, mães, familiares, amigos e amigas de nossos formandos, Caros e caras formandos e formandas: Ana Claudia Monteiro dos Santos; Gracileide de Jesus Cantanhede Reis; Iraceles Cardoso Luzo; João Matheus Nascimento Rodrigues; Leandro Chagas Lima; Kacio Micael Oliveira Vidal; Nivia Leticia Diniz Moura; Patricia Assuncao Ferreira; Pedro Nascimento Corrêa; Rayanne Ferreira Coelho; Suyanne Claire Lopes; Taynara de Sousa Mendes; Wesley Soares da Silva.

Da surpresa inicial do convite e do impacto por ter sido a escolhida por vocês para ser a paraninfa da turma 2020.1 do Curso de Biblioteconomia da Universidade Federal do Maranhão, só posso expressar um sentimento agora: gratidão! Grata porque, embora já tenha recebido outras homenagens de turmas durante meus 28 anos de docência, esta me é muito cara e especial! Primeiro, porque é a primeira vez que sou paraninfa e, segundo, porque cada um de vocês acreditou que algo que eu pudesse pensar e expor na minha experiência profissional, nos conhecimentos transmitidos, nos ensinamentos ofertados seria, de alguma forma, importante para vocês! Assim como também souberam aproveitar de todos os outros professores e professoras, tanto é que, hoje, estão aqui, nesta solenidade de formatura, graduandose em Bacharel de Biblioteconomia! Lembro, com muito carinho, da forma especial com que cada um me chegou, sendo ou não meu aluno /minha aluna.

Guardo na, "parede da memória", parafraseando Belchior, as lembranças que, embora não estejam em um quadro, ficarão sempre registradas no meu pensamento. Com alguns de vocês tive a oportunidade de conviver com maior intensidade, por terem sido do Programa de Educação Tutorial do qual ainda estou como tutora, de

\footnotetext{
${ }^{1}$ Doutora em Políticas Públicas e Professora Associada III do Departamento de Biblioteconomia, da Universidade Federal do Maranhão. E-mail: maria.alencar@ufma.br. Orcid: http://orcid.org/00000003-4829-1241.
} 
modo especial, Wesley, Taynara e Kacio. Outros, no alegre convívio presencial das salas de aula, que, no momento presente, infelizmente, nos foi furtado pelo período pandêmico que todos estamos atravessando, inclusive afetando esta solenidade, o que a torna mais especial ainda! Eu ficarei conhecida como a $1^{\underline{a}}$ paraninfa virtual do Curso de Biblioteconomia da UFMA! E vocês, os responsáveis por tal feito! E por falar em pandemia, não quero thes falar, meus caros e caras alunos e alunas, das coisas que aprendi nos livros, para continuar com um dos meus poetas preferidos, o nosso inesquecível Belchior.

Quero Ihes contar como podemos, nós bibliotecários, enfrentar cenário tão adverso! Vocês são a nossa aposta para a mudança, a preocupação existe em vocês! Não foi à toa que os temas das monografias desta turma foram tão atuais, inéditos e questionadores! Da (des)informação pelas Fake News, de Suyanne, à produção colaborativa e o rock heavy metal, de Taynara, nos oportunizaram adquirir novos conhecimentos. Sim! O rock, este gênero musical tão revolucionário e polêmico, entrou na esfera acadêmica de interesse de estudo da Biblioteconomia, o que resultou em um trabalho brilhante! $E$ a diversidade de temas e de trabalhos de excelência não parou por aí! Ana Cláudia e a sua veemente preocupação com o estágio obrigatório na Biblioteca Central da UFMA; O arquivo da Federação dos Trabalhadores e das Trabalhadoras Rurais, Agricultores e Agricultoras do Maranhão esteve presente na interessante narrativa de Gracileide; Iraceles e o seu olhar curioso sobre os portais de periódicos científicos das universidades públicas do Maranhão; as representações também se fizeram presentes sob a análise inovadora de João Matheus e sua sumarização automática e Nívia Letícia, com o seu iluminado exame sobre as práticas descritivas na biblioteca da UEMA; Leandro se aventurou fortemente em compreender o módulo de gerenciamento de bibliotecas do Sigaa da Diretoria Integrada de Bibliotecas da UFMA; a preocupação com os deficientes também se fez presente sob a atenção primorosa de Kacio, ao descrever as tecnologias assistivas para estudantes com deficiência visual; até projeto premiado foi alvo de estudos e análise por Patrícia, que se interessou preciosamente, claro, pelo Projeto de Extensão Formação Discente Pesquisador; esteve na pauta das monografias defendidas também a consultoria de marketing em bibliotecas, na perspectiva apurada de Rayanne; e, claro, não poderia faltar, nesta lista, as tão atuais e utilizadas mídias sociais traçando o perfil do Cais da Leitura que Pedro, tão entusiasticamente, 
apresentou; e finalmente, Wesley, que elaborou uma distinta investigação sobre a acessibilidade web e governo eletrônico do portal da Secretaria de Estado da Cultura do Maranhão.

Assim, caros e caras formandos e formandas de Biblioteconomia, o desafio está posto! Com temas tão instigadores e relevantes para a nossa área, não podemos nos furtar de contribuir para que o panorama bibliotecário seja alterado. Da necessidade de implantação de bibliotecas escolares na rede pública ao uso de inúmeras e sofisticadas tecnologias, há um grande fosso! Estamos "dançando na corda bamba", porque se, de um lado, temos a tão propagada "Sociedade da Informação", por outro, temos uma legião de excluídos! Já nos dizia Kurz (2002, não paginado) que:

A maravilhosa sociedade do conhecimento aparece, ao que tudo indica, justamente por isso, como sociedade da informação porque se empenha em reduzir o mundo a um acúmulo de informações e processamentos de dados e em ampliar, de modo permanente, os campos de aplicação destes.

E vocês deverão ocupar tão vastos campos de atuação para a Biblioteconomia. Cabe a nós e a vocês, concludentes, a reinvenção, não é essa a palavra em voga atualmente? Entretanto, tentam nos ofertar uma ideia aparente de que, por meio dos recursos midiáticos que a sociedade atual dispõe, seria possível uma nova ordem econômica, mas o que se verifica é que tal argumento é nada mais do que uma tentativa de mascarar as reais contradições existentes no modo de produção vigente. Ou seja: o discurso da "sociedade da informação" está completamente descolado do que se presencia no atual estágio do capitalismo.

O desenvolvimento das Tecnologias de Informação e Comunicação, caracterizado como um dos elementos determinantes dessa nova era, está intrinsecamente relacionado ao processo de mundialização do capital, à reestruturação produtiva e aos fenômenos que deles decorrem, como: o desemprego, a flexibilização, a precarização do trabalho e a perda de conquistas sociais por parte dos trabalhadores (BOLAÑO, 2005, p. 2). Além disso, estamos atravessando momentos que julgávamos termos superado, porém, para espanto nosso, o Brasil mostrou a sua cara ao colocar na direção do país pessoas capazes de taxar impostos sobre livros (que nos são tão preciosos) e liberar taxas para importação de armas!!!

Vivenciamos, no nosso cotidiano, situações que estão se tornando normais, quando o certo seria considerarmos anormais! Estão naturalizando quase 200 mil 
mortes ocasionadas pelo corona-vírus e ignorando e politizando um plano emergencial de vacinação! Assim, neste cenário tão cruel, foram-se, dentre tantos, os Rubens, as Sônias e as Magnólias, mestres queridos e admirados, que nos inspiraram muito e a quem devemos tanto! E foram-se, também, os Aldir, os Ciros, os Moraes, as Fabianas, as Dulces e os Paulinhos, todos embarcados por esse contagioso vírus, e nem sequer uma nota oficial fora emitida, não a musical, mas a de solidariedade! $E$ foram-se os anônimos enfileirados... Elis, com sua consagrada voz, interpretando João Bosco e o nosso saudoso Aldir Blanc (que morreu também vítima de Covid), na canção "O Bêbado e a Equilibrista", ainda em 1979, cantava: "Chora A nossa Pátria mãe gentil; Choram Marias e Clarisses no Solo do Brasil".

Nas favelas, crianças, principalmente as negras, ampliam as estatísticas nos jornais pelas suas vidas ceifadas! Jovens negros são cotidianamente assassinados ou presos, sem direito a comprovarem a sua inocência! E nós mulheres, quantas violências mais teremos que sofrer e quantas mortes mais farão parte deste quantitativo? E o amor? É proibido amar nesse país? Até quando ficaremos acorrentados em dogmas e padrões em que o amor não pode mais ser livre? Que país é este, Legião Urbana? Será que vamos perder a capacidade de acreditar que as flores vencem os canhões? Ah! Nós temos que buscar a poesia né Geraldo (VANDRÉ, 1968), volte pra nos chamar pra fazer a hora (ou o agora!) e não esperar acontecer! Precisamos reagir! Urgentemente! E nós, bibliotecários e bibliotecárias temos um papel preponderante nesses tempos tão sombrios, afinal, somos há muito considerados importantes agentes de mudanças! Cadê a nossa ação guerrilheira, Oswaldo (ALMEIDA JÚNIOR, 1995) que tão belo narrou no seu ensaio sobre a biblioteca pública? Ou, será que nada disso nos atinge? Será que ainda continuaremos a ser conhecidos como os arrumadores de livros? Não! A catalogação, a classificação, a organização etc., de modo geral precisam estar atentas a esse movimento social! Afinal, a Biblioteconomia é social por essência!

A nossa aparência talvez ainda insista em caricaturizar o silêncio nas bibliotecas, mas a nossa força, expressa por nossa voz e nosso fazer não nos calará! À Biblioteconomia urge mostrar o que somos, para que somos e a quem queremos servir! Não podemos nos isolar desse tecido social, ou será que cada um ou uma de nós não já sentiu na pele o preconceito, as injustiças e as desigualdades sociais? Quantas Marias e Joãos não se identificam com aquela "gente que ri quando deve 
chorar, E não vive, apenas aguenta?" Milton (NASCIMENTO, 1978) na sua canção Maria, Maria nos ensina, e diz "é preciso ter força, é preciso ter raça, É preciso ter gana sempre; Quem traz no corpo essa marca [...] Mistura a dor e a alegria". E vocês, meus queridos e queridas formandos e formandas, precisam estar atentos e fortes, já nos diria Caetano (VELOSO, 1968, não paginado), "[...] sem tempo de temer a morte, Atenção ao pisar o asfalto, o mangue. Atenção para o sangue sobre o chão. Atenção. Tudo é perigoso. Mas, tudo também pode ser divino maravilhoso." Afinal, "Nós queremos ser feliz agora", né Oswaldo? o Montenegro (2010), porque "Se alguém vier com papo perigoso de dizer que é preciso paciência pra viver, Que andando ali quieto, Comportado, limitado, Só coitado, você não vai se perder, Que manso imitando uma boiada, você vai boca fechada pro curral sem merecer [...] Que você volte pro rebanho, Não acredite, grite, sem demora[..], porque nós queremos ser feliz agora!"

"Não temos tempo a perder, Nosso suor sagrado, É bem mais belo que esse sangue amargo [e armado]." (LEGIÃO URBANA, 1986). E nós, vamos tomar vacina, quem não quiser que tome cloroquina, né Chico (CÉSAR, 2020)?

Muito obrigada!

São Luís, 17 de dezembro de 2020.

\section{REFERÊNCIAS}

ALMEIDA JUNIOR, Oswaldo F. Biblioteca pública: ambiguidade, conformismo e ação guerrilheira do bibliotecário. Ensaios APB, n.15. São Paulo, 1995.

BOLAÑO, César Ricardo Siqueira. Sociedade da informação, reestruturação produtiva e economia do conhecimento. Telos, jul./set. 2005. Disponível em: http://www2.eptic.com.br/sgw/data/bib/artigos. Acesso em: 12 ago. 2012.

CÉSAR, Chico. Eu vou tomar vacina, quem não quiser que tome cloroquina. 2020. 1 vídeo. Disponível em: https://www.youtube.com/watch?v=i8cxicXwNrU. Acesso em: 15 dez. 2020.

KURZ, Robert. A ignorância da sociedade do conhecimento. Folha de São Paulo, São Paulo, 13 jan. 2002. Caderno Mais, p.14. Disponível em: https://www1.folha.uol.com.br/fsp/mais/fs1301200211.htm. Acesso em: 15 dez. 2020. 
LEGIÃO URBANA. Tempo perdido. 1986. Disponível em:

https://www.letras.mus.br/legiao-urbana/22489/. Acesso em: 15 dez. 2020.

MONTENEGRO, Oswaldo. Eu quero ser feliz agora. 2010.Disponível em: https://www.letras.mus.br/oswaldo-montenegro/1934063/. Acesso em: 15 dez. 2020.

NASCIMENTO, Milton. Maria, Maria. 1978. Disponível em:

https://www.letras.mus.br/milton-nascimento/47431/. Acesso em 15 dez. 2020.

VANDRÉ, Geraldo. Pra não dizer que não falei das flores. 1968. Disponível em: https://www.letras.mus.br/geraldo-vandre/46168/. Acesso em: 15 dez. 2020.

VELOSO, Caetano. Divino maravilhoso. 1968. Disponível em:

https://www.letras.mus.br/caetano-veloso/44718/. Acesso em: 15 dez. 2020.

Submissão: 1 fev. 2021

Aprovação: 5 fev. 2021 